\title{
COMPARTIVE STUDY BETWEEN UNIPORT VIDEO-ASSISTED THORACOSCOPY AND CERVICAL MEDIASTINOSCOPY IN MEDIASTINAL LYMPH NODE BIOPSY
}

Ahmed Saleh Abu Elkasem, Mostafa Mohammed Kamel El-Hammamy, Ahmed Anwar Saad, Abdelhamid Ahmed Ghazal, Mahmoud Abbas Moustafa Elkhayat Department of Cardiothoracic Surgery, Department of General surgery, Faculty of Medicine, Alexandria University

\section{Initroduction}

The four most common causes of mediastinal lymphadenopathy are sarcoidosis, lymphoma, and metastatic carcinoma, and granulomatous infections.

Lymph node locations have been traditionally divided into 14 stations according to surgical landmarks from mediastinoscopy and thoracotomy.

\begin{tabular}{|c|c|}
\hline Nodal Zone & Lymph node station \\
\hline \multirow{4}{*}{ Upper zone } & Low cervical, supraclavicular, sternal notch $(1 \mathrm{R}-1 \mathrm{~L})$ \\
\hline & Upper paratracheal $(2 \mathrm{R}-2 \mathrm{~L})$ \\
\hline & Prevascular (3A) and retrotracheal (3P) \\
\hline & Lower paratracheal $(4 \mathrm{R}-4 \mathrm{~L})$ \\
\hline \multirow{2}{*}{ Aortopulmonary zone } & Subaortic (aortopulmonary window - 5) \\
\hline & Para-aortic (ascending aorta or phrenic nerve - 6) \\
\hline Subcarinal zone & Subcarinal $(7)$ \\
\hline \multirow{2}{*}{ Lower zone } & Paraesophageal (8) \\
\hline & Pulmonary ligament $(9)$ \\
\hline \multirow{2}{*}{ Hilar zone } & Hilar (10) \\
\hline & Interlobar superior (11 S) and inferior (11 I) \\
\hline \multirow{3}{*}{ Peripheral zone } & Lobar (12) \\
\hline & Segmental (13) \\
\hline & Subsegmental (14) \\
\hline
\end{tabular}

Selection of the biopsy procedure depends on the lymph node station and full patient history of prior neck and thoracic surgery. The procedure options include cervical mediastinoscopy, thoracoscopy, anterior mediastinotomy, endobronchial ultrasound, navigational bronchoscopy, and esophageal ultrasound.

\section{Aim of the work}

The aim of this study was to compare between the efficacy, accessibility and safety of uniport VATS and cervical mediastinoscopy in mediastinal lymph node biopsy for both station $2 \mathrm{R}$ and $4 \mathrm{R}$.

\section{Patilents and Methods}

The present study was carried out on 24 patients who were presented with mediastinal lymphadenopathy admitted at Cardiothoracic Surgery Department University of Alexandria.

Patients were randomly divided into two groups 12 patients each. Group I included 12 patients in whom Mediastinoscopic lymph node biopsy was performed.

Group II included 12 patients in whom VATS lymph node biopsy was performed.
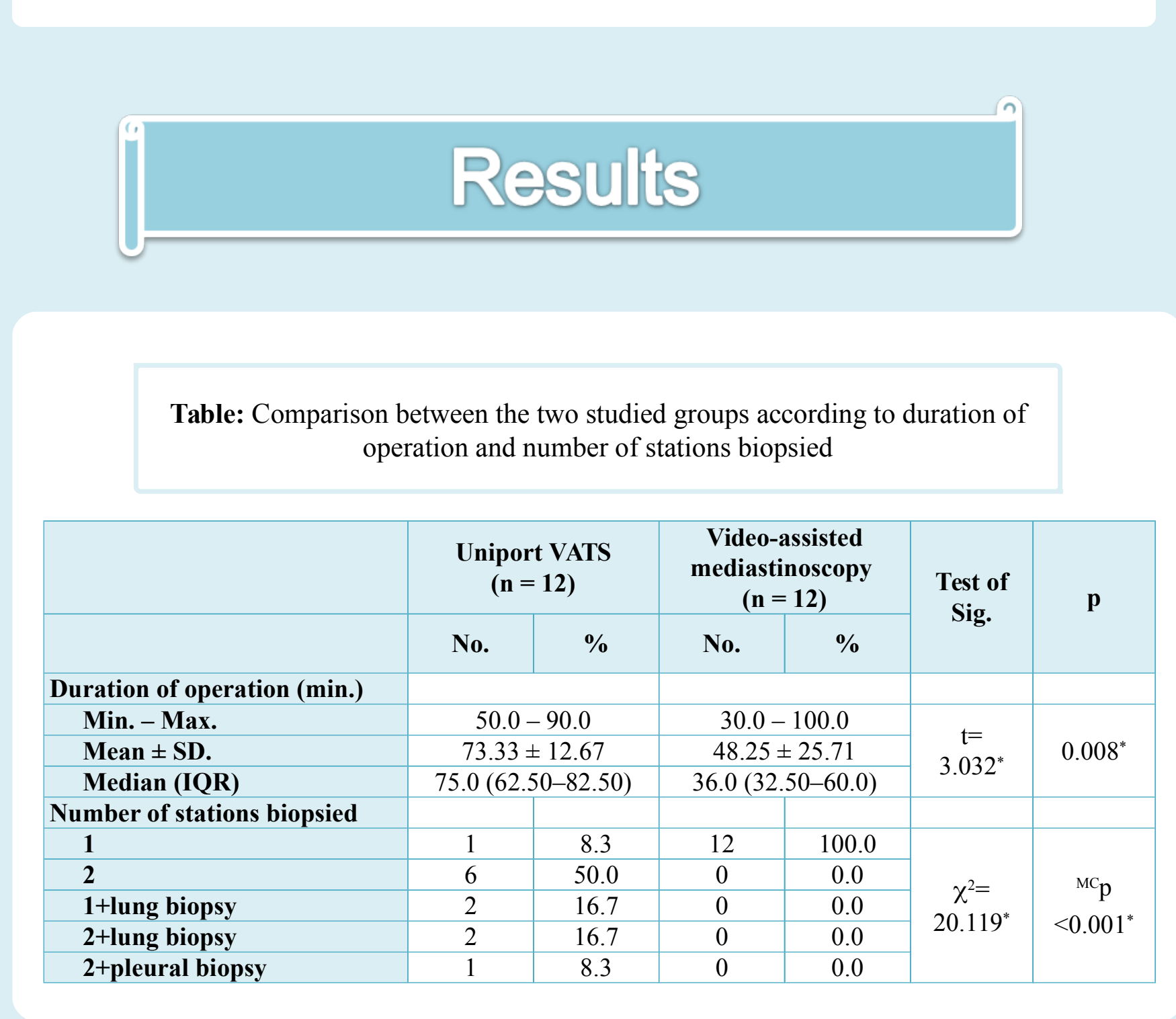

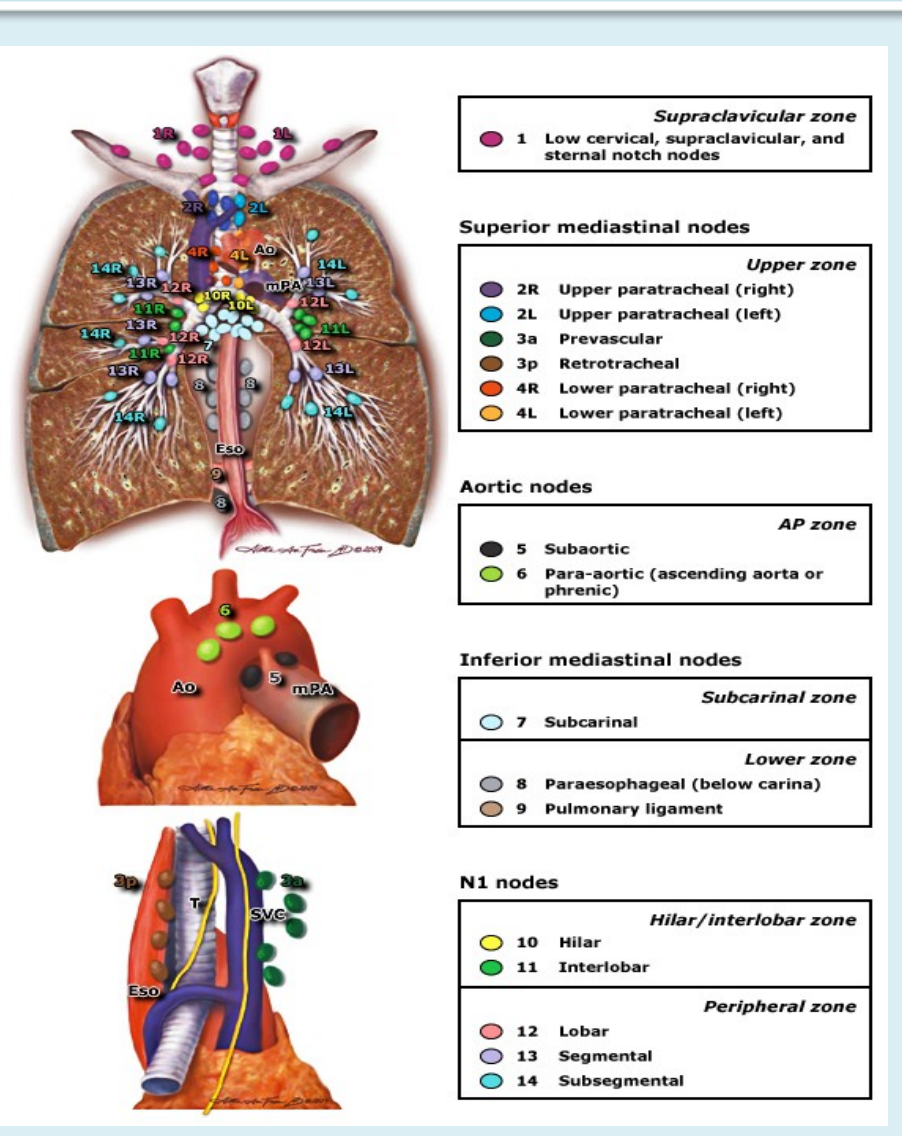

Figure: Stations of mediastinal L.N

\section{Conctusion}

Comparison between the two studied groups according to duratio of operation was less in mediastinoscopy $(\mathrm{p}=0.008)$, post-operative hospital stay showed that mediastinoscopy had less hospital stay than thoracoscopy $(\mathrm{p}<0.001)$.

By Comparing the two groups according to accessibility of other biopsies showed that lung, pleural and other ipsilateral L.N biopsies can be obtained via thoracoscopy $(\mathrm{p}<0.001)$.

$$
\begin{gathered}
\text { 20210Alexandria Faculty of Medicine } \\
\text { CC-BY-NC }
\end{gathered}
$$

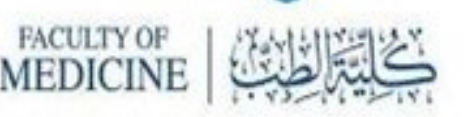

